\title{
Adhesion of Epoxy Resin Based Endodontic Sealers to the Root Canal with and Without Smear Layer Removal
}

\author{
Dr Sheena. $\mathrm{P}^{1}$, Dr Indu Raj ${ }^{2}$, Dr Roshini Ramesh ${ }^{3}$, Dr Christalin $\mathrm{R}^{4}$ \\ ${ }^{I}$ Department of Conservative Dentistry and Endodontics, Government Dental College, Government TD Medical \\ College Campus, Alappuzha, KUHS University, Kerala, India. \\ ${ }^{2}$ Department of Prosthodontics, Government Dental College, Government TD Medical College Campus, \\ Alappuzha, Kerala, India. \\ ${ }^{3}$ Department of Periodontics, Government Dental college, Thrissur, KUHS University, Kerala, India. \\ ${ }^{4}$ Department of conservative dentistry, Government Dental college, Thrissur, KUHS University, Kerala, India.
}

\begin{abstract}
To study the adhesion of epoxy resin based endodontic sealers by determining the tensile bond strength and evaluating the effect of smear layer removal on the adhesion of the endodontic sealers. Root canals of freshly extracted mandibular first premolar teeth with single root canal, were instrumented by using rotary instrument The roots were prepared for adhesion by splitting them and embedding them in self cure acrylic block. The specimens were randomly divided into 4 groups of 10 teeth each according to the sealer used and their irrigation regimen. AH Plus and AH-26 sealers were compared for their adhesion with and without smear layer. The test specimens were subjected to a tensile force in a universal testing machine. Statistical analysis revealed that mean tensile bond strength of AH-26 increased after treatment with 17\% EDTA .Conversely the tensile bond strength of AH Plus sealer decreased after the treatment with 17\% EDTA. Different sealer types require different dentine pre-treatment's for optimal adhesion.
\end{abstract}

Keywords: $\quad$ Root canal sealer, Smear layer, Tensile bond strength.

\section{Introduction}

One of the principal goals of successful endodontic therapy is complete root canal obturation that provides a biological environment for healing of the periradicular tissues [1].In order to achieve this a proper seal is required to negate any future bacterial invasion. Sealer enhances the possible attainment of an impervious seal and serves as a filler for root canal irregularities and micro discrepancies between root canal wall and core filling materials. A good sealer must have adhesive strength to dentin and to the core material. [2]. In addition sealer must have cohesive strength to hold the obturation together Adhesive dental materials are now available that may offer an opportunity to reinforce the endodontically treated tooth through the use of adhesive sealers in the root canal system. [3].Therefore recent attention has been focused to adhesive properties of root canal sealers.

The present study was undertaken to evaluate the relative strength of two epoxy resin based root canal sealers, AH-26 and AH Plus by measuring the tensile bond strength and also to examine the effect of smear layer on the adhesion of these two sealers.

\section{Review of literature}

Filling of root canal system and all its complex anatomical pathways frequently uses semisolid materials such as gutta-percha in combination with root canal sealer. Currently the rationale for use of endodontic sealer is the assumption that the sealer forms a fluid tightly seal and barrier apically, laterally and coronally between the dentin and gutta percha and that the sealer fills the space between gutta percha cones. Over the years several methods have been tested to improve the adhesion of root canal sealers to radicular dentine. Ideally a root canal filling material provide a barrier that prevent bacterial ingress from the oral cavity. Only a few studies have attempted to evaluate the adhesive properties of root canal sealers by measuring their bond strengths. $[4,5,6]$ These studies have investigated the effect smear layer removal on sealer adhesion with controversial results. It has been suggested that endodontic smear layer acts as a physical barrier interfering with adhesion and penetration of sealers in to dentinal tubules, which may affect the sealing efficacy of root canal obturation. Studies were conducted to assess the influence of smear layer on the dentinal penetration of by different root canal sealers. Studies conducted on adhesion of endodontic sealers by scanning electron microscopy and energy dispersive spectroscopy has shown that penetration of endodontic sealers in to the dentinal tubules when the smear layer was removed was not associated with higher bond strength .[7] 


\section{Materials and Methods}

The two epoxy resin based root canal sealers used in this study are AH26 (silver free) and AH plus.

\section{AH 26(Silver free)}

Powder and liquid are mixed on a glass slab using a metal spatula.2-3 volume units of powder are mixed with 1 volume unit of resin. The cement is mixed to homogenous consistency which breaks when lifted 1.5 to $2.5 \mathrm{~cm}(1 / 2$ to 1 inch)above the glass slab. The setting time of this cement is between 9 and 15 hours at $37^{0} \mathrm{C}$.

\section{AH Plus}

Equal volume units(1:1)of paste A and paste B is mixed on a glass slab or mixing pad using metal spatula and mixed for a homogenous consistency. Mixing ratio by weight is $1 \mathrm{~g}$ paste A to $1.8 \mathrm{~g}$ paste $\mathrm{B}$. The working time of the cement is minimum 4 hours at $23^{\circ} \mathrm{C}$ and setting time is a minimum of about 8 hours at $37^{\circ} \mathrm{C}$. Irrigating solutions used were $0.9 \%$ physiological saline, $5.25 \%$ Sodium hypochlorite, $17 \%$ Ethylene diamine tetraaceticacid (EDTA) and Distilled water.

\subsection{Preparation of samples}

40 mature mandibular first premolar teeth with single root canal, extracted from patients between the age group of 18-30 years for orthodontic correction were used in this study.

\section{Criteria for the selection of teeth were}

1) single rooted single canal teeth.

2)straightness of canal till the apex or canals with curvature not more than 2 to $5^{0}$ to the long axis of the teeth.

3)Fully developed apices.

The teeth were cleaned off superficial debris using a scalpel to remove all adhering soft tissue and stored in $0.9 \%$ physiological saline solution until ready for use. The teeth were randomly divided into 4 groups of 10 teeth each. The root canals were instrumented and the roots were prepared for adhesion as follows. Longitudinal grooves were made on the buccolingual surface of the root to a depth that almost exposed the root canal wall. Roots were then split into two parts. One half of the root canal was used to for testing. The flat inner wall of the root canal was further prepared by smoothing the canal wall .The teeth were embedded in self-cure acrylic resin block leaving the flat surface of the root at the level of of the resin block. "Fig-1". After the resin had set, the dentin surface was polished with 600 grit silicon carbide paper. The smear layer was not disturbed. The amount of irrigant used in each canal was carefully controlled.

In Group I (AH 26 -saline group), initially the dentin surface was treated with $10 \mathrm{ml}$ of $0.9 \%$ saline for 3 minutes. The final irrigating solution used was $3 \mathrm{ml}$ of $5.25 \% \mathrm{NaOCl}$ followed by $3 \mathrm{ml}$ of distilled water for 3 minutes each. In Group II (AH26- EDTA) instead of saline ,100ml of 17\% EDTA was used for 3 minutes. The final irrigating solution was as in group I. In Group III (AH Plus- saline) the same sequence of irrigation as in group I is used .In Group IV (AH Plus- EDTA) the same sequence of irrigation as in group II is followed.

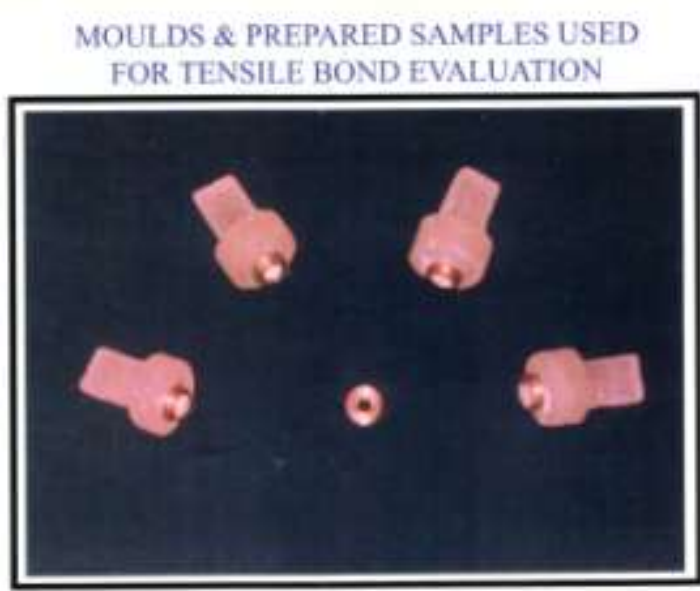

Fig-1. samples embedded in resin blocks.
HOLDING DEVICE \& MOULD

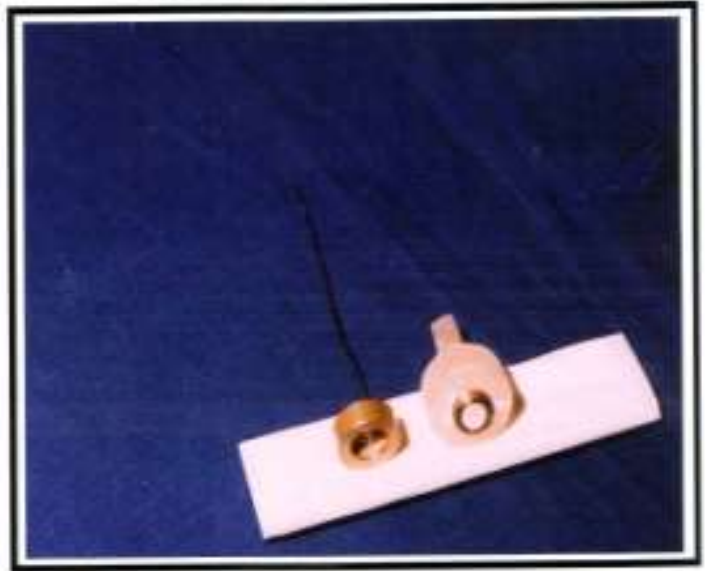

Fig-2. Holding device and mould. 


\subsection{Testing of tensile bond strength}

Brass rings having $4 \mathrm{~mm}$ inner diameter and $3 \mathrm{~mm}$ height was made. These rings were threaded on the outer side for adaptation into a holding device. These rings were centred over the flat dentin surface and attached to to dentin by sticky wax.

In group I and group II the sealer AH26 was used to fill the brass ring. The sealer was mixed according to the manufacturer's instruction to a uniform consistency. The freshly mixed sealer was carefully placed into the brass ring with one side contacting the dentin taking care to avoid entrapment of air bubbles. In group III and group IV ,the sealer was used following the above precautions. After the initial set, they were transferred to an incubator at $37^{\circ} \mathrm{C}$ for 48 hours.

\subsection{Preparation for scanning electron microscopy}

Two specimen were used to verify the smear layer by SEM observation. One specimen was treated with $0.9 \%$ saline and the other one had the smear layer removed with $17 \%$ EDTA. The specimens were mounted in graded series of ethanol solution for dehydration. The specimens were mounted on aluminium stubs, vacuum dried and coated with thick gold-palladium layer. The root surfaces were observed under the scanning electron microscope.

\subsection{Testing the specimen}

The samples prepared for testing the tensile bond were mounted onto the lower jaw of the universal testing machine (Instron model 1011,Instron Co.UK).The machine was interfaced with a computer through which operation of the equipment was controlled and tensile bond strength was calculated. A 25 gauge stainless steel wire loop was hooked onto the holding device. The holding device was fitted onto the threaded brass ring with sealer in space. "Fig-2." The stainless steel wire is attached to the upper jaw of the universal testing machine which is activated to move upwards at a cross head speed of $1 \mathrm{~mm} /$ minute. The tensile load required to fracture the bond was recorded in Kilo Newton and the bond strength was calculated in MPa.

\section{Results and observations.}

The load at break and resulting bond and resulting bond strength recorded during the tensile bond testing using sealers AH-26 and AH Plus are listed in tables. In order to compare the different groups ,the stastical constants like mean, standard deviation etc were tested with the help of student's' test. The diagrams and charts were drawn wherever necessary to substantiate the important findings. From the table IV it is inferred that the mean tensile bond strength of Group I (AH saline group) is $4.2332 \mathrm{Mpa}$ with the standard deviation of $1.7020 \mathrm{Mpa}$ and standard error mean of 0.6948. For group II ie (AH -26 EDTA group), the tensile bond strength computed was 4.3242 $\mathrm{MPa}$ with the standard deviation 1.9253 and standard error mean of 0.7860 . Students ttest for equality of means was carried out and computed $(\mathrm{t}=0.087, \mathrm{p}=0.933)$. The comparison of group I and II showed that there was no statistically significant difference between the two group. $(\mathrm{p}>0.05)$. However numerically group II showed slightly better result than group II. Table VII, compares the tensile bond strength of group III and IV. It is noted from the table that the mean tensile bond strength of group III(AH Plus saline group) was about 5.1733 MPa and that of group IV (AH Plus EDTA group) was about 3.1967. The mean deviation of group III was about 2.1827 with standard error of 0.9811 .The group IV had the standard deviation of about 0.8808 with the standard turned out to be statistically insignificant. $(p>0.05)$.

TABLE I

Group I.AH-26 saline

\begin{tabular}{|l|l|l|l|}
\hline $\begin{array}{l}\text { Specimen } \\
\text { No. }\end{array}$ & $\begin{array}{l}\text { Load at break } \\
\text { (Newton) }\end{array}$ & $\begin{array}{l}\text { Surface area } \\
\mathrm{Mm}^{2}\end{array}$ & $\begin{array}{l}\text { TBS } \\
\mathrm{MPa}\end{array}$ \\
\hline 1 & 70.5 & 12.560 & 5.6136 \\
\hline 2 & 64.0 & 12.560 & 5.0960 \\
\hline 3 & 31.0 & 12.560 & 2.4680 \\
\hline 4 & 22.6 & 12.560 & 1.8010 \\
\hline 5 & 73.9 & 12.560 & 5.8810 \\
\hline 6 & 57.1 & 12.560 & 4.5480 \\
\hline 7 & 57.7 & 12.560 & 4.040 \\
\hline 8 & 55.6 & 12.560 & 4.430 \\
\hline
\end{tabular}

Group III AH Plus -saline
TABLE II Group II.AH-26 EDTA

\begin{tabular}{l|l|l|l|l|}
\hline $\begin{array}{l}\text { Specimen } \\
\text { No. }\end{array}$ & $\begin{array}{l}\text { Load at break } \\
\text { (Newton) }\end{array}$ & $\begin{array}{l}\text { Surface area } \\
\mathrm{Mm}^{2}\end{array}$ & $\begin{array}{l}\text { TBS } \\
\text { MPa }\end{array}$ \\
\cline { 2 - 5 } & 1 & 50.9 & 12.560 & 4.080 \\
\hline 2 & 93.6 & 12.560 & 7.454 \\
\hline & 3 & 76.0 & 12.560 & 5.762 \\
\hline 4 & 30.0 & 12.560 & 2.389 \\
\hline \multirow{4}{*}{$\begin{array}{l}\text { TA } \\
\text { BLE }\end{array}$} & 5 & 40.4 & 12.560 & 3.215 \\
\cline { 2 - 5 } & 6 & 38.3 & 12.560 & 3.045 \\
\cline { 2 - 5 } & 7 & 55.892 & 12.560 & 4.45 \\
\cline { 2 - 5 } & 8 & 52.751 & 12.560 & 4.20 \\
\hline
\end{tabular}

TABLE IV 
Adhesion of Epoxy Resin Based Endodontic Sealers to the Root Canal with and Without Smear Layer Removal

\begin{tabular}{|l|l|l|l|}
\hline $\begin{array}{l}\text { Specimen } \\
\text { No. }\end{array}$ & $\begin{array}{l}\text { Load at break } \\
\text { (Newton) }\end{array}$ & $\begin{array}{l}\text { Surface area } \\
\mathrm{Mm}^{2}\end{array}$ & $\begin{array}{l}\text { TBS } \\
\mathrm{MPa}\end{array}$ \\
\hline 1 & 63.4 & 12.560 & 5.045 \\
\hline 2 & 43.5 & 12.560 & 3.463 \\
\hline 3 & 55.5 & 12.560 & 4.419 \\
\hline 4 & 34.1 & 12.560 & 2.717 \\
\hline 5 & 78.0 & 12.560 & 8.583 \\
\hline 6 & 85.5 & 12.560 & 6.807 \\
\hline 7 & 66.8 & 12.560 & 5.320 \\
\hline 8 & 63.1 & 12.560 & 5.029 \\
\hline
\end{tabular}

$\mathrm{TAB}$

\begin{tabular}{|l|l|l|l|}
\hline $\begin{array}{l}\text { Specimen } \\
\text { No. }\end{array}$ & $\begin{array}{l}\text { Load at break } \\
\text { (Newton) }\end{array}$ & $\begin{array}{l}\text { Surface area } \\
\mathrm{Mm}^{2}\end{array}$ & $\begin{array}{l}\text { TBS } \\
\mathrm{MPa}\end{array}$ \\
\hline 1 & 29.1 & 12.560 & 2.319 \\
\hline 2 & 54.6 & 12.560 & 4.349 \\
\hline 3 & 47.8 & 12.560 & 3.802 \\
\hline 4 & 37.0 & 12.560 & 2.946 \\
\hline 5 & 45.8 & 12.560 & 3.643 \\
\hline 6 & 27.6 & 12.560 & 2.199 \\
\hline 7 & 41.2 & 12.560 & 3.283 \\
\hline 8 & 39.5 & 12.560 & 3.152 \\
\hline
\end{tabular}

LE V

Mean and standard deviation of tensile bond strength

in group I\& II and level of significance

\begin{tabular}{|l|l|l|l|l|}
\hline Group & $\mathrm{N}$ & Mean & Std.dDviation & Std.error \\
\hline AH-26 saline & 8 & 4.2332 & 1.7020 & 0.6948 \\
\hline AH-26 EDTA & 8 & 4.3242 & 1.9253 & 0.7860 \\
\hline
\end{tabular}

\begin{tabular}{|c|c|c|}
\hline \multirow{3}{*}{ Tensile strength } & \multicolumn{3}{c}{$\begin{array}{l}\text { Independ samples Test } \\
\text { test for equality of means }\end{array}$} \\
\cline { 2 - 3 } & $\mathrm{T}$ & $\mathrm{p}$ \\
\cline { 2 - 3 } & 0.087 & 0.933 \\
\hline
\end{tabular}

TABLE VI

Mean and standard deviation of tensile bond strength in group III\& IV and level of significance

\begin{tabular}{|l|l|l|l|l|}
\hline Group & $\mathrm{n}$ & Mean & Std.Deviation & Std.error \\
\hline AH-Plus saline & 8 & 5.1733 & 2.1827 & 0.8911 \\
\hline AH-Plus EDTA & 8 & 3.1967 & 0.8808 & 0.3596 \\
\hline
\end{tabular}

\section{TABLE VII}

Mean and standard deviation of tensile bond strength in group I \& III and level of significance

\begin{tabular}{|l|l|l|l|l|}
\hline Group & $\mathrm{n}$ & Mean & Std.dDviation & Std.error \\
\hline AH-26 saline & 8 & 4.2332 & 1.7020 & 0.6948 \\
\hline AH-Plus saline & 8 & 5.1733 & 2.1827 & 0.8911 \\
\hline
\end{tabular}

\section{TABLE VIII}

Mean and standard deviation of tensile bond strength in group II \& IV and level of significance

\begin{tabular}{|l|l|l|l|l|}
\hline Group & $\mathrm{n}$ & Mean & Std.Deviation & Std.error \\
\hline AH-26 saline & 8 & 4.3242 & 1.9253 & 0.7860 \\
\hline AH-Plus saline & 8 & 3.1967 & 0.8808 & 0.3596 \\
\hline
\end{tabular}

Independent samples Test

\begin{tabular}{|c|c|c|}
\hline \multirow{2}{*}{ Tensile strength } & \multicolumn{2}{|c|}{$\mathrm{t}$ test for equality of means } \\
\cline { 2 - 3 } & $\mathrm{t}$ & $\mathrm{p}$ \\
\cline { 2 - 3 } & 1.304 & 0.221 \\
\hline
\end{tabular}

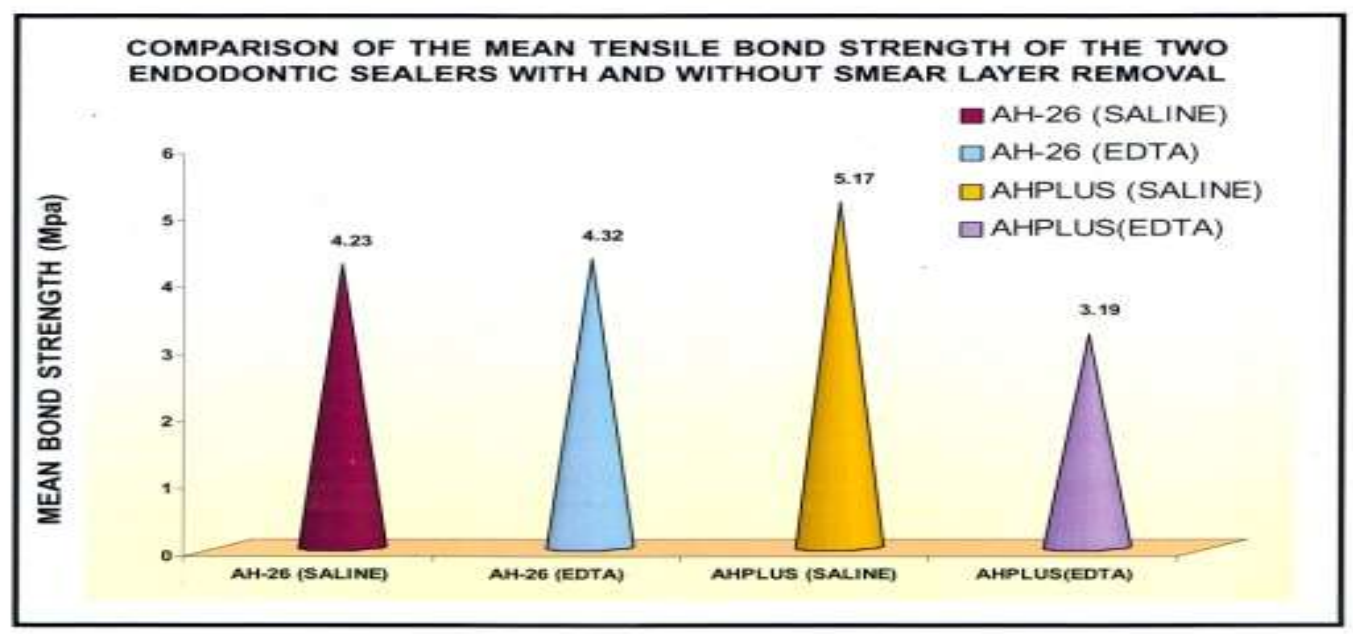

Fig-3 - comparison of mean tensile bond strength of AH-26 and AH Plus 
COMPARISON OF THE MEAN LOAD AT BREAK OF THE TWO SEALERS WITH AND WITHOUT SMEAR LAYER REMOVAL

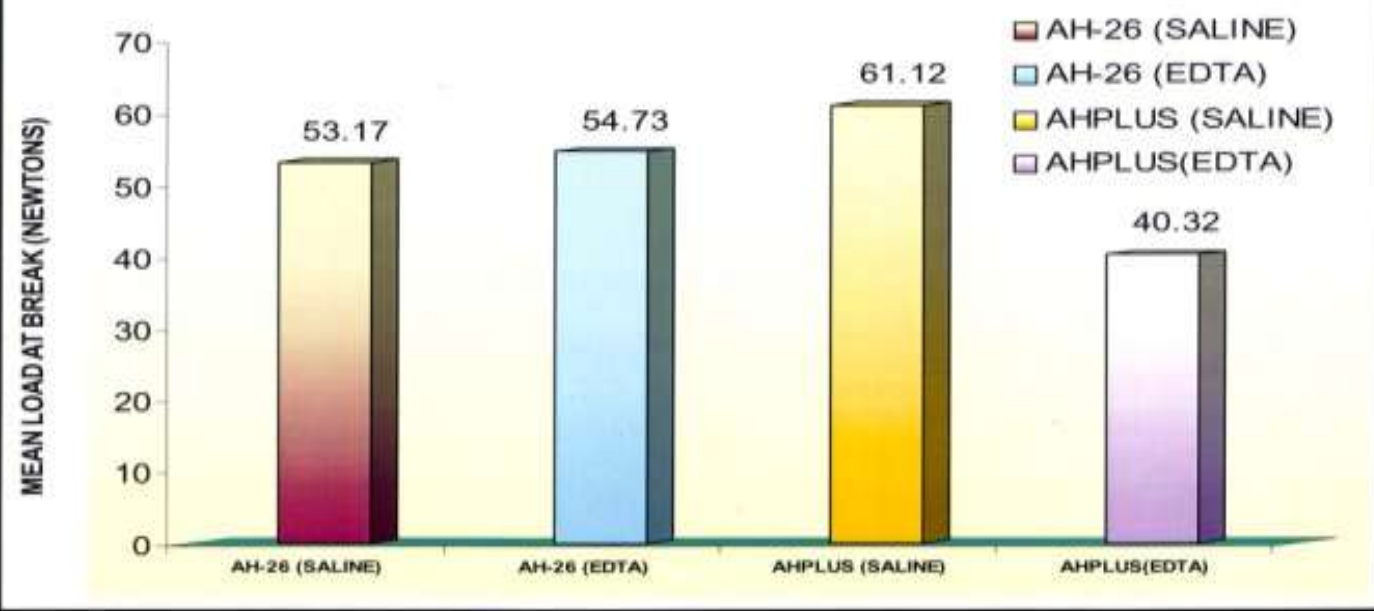

Fig-4 -comparison of mean load at break of AH-26 and AH Plus with and without smear layer.

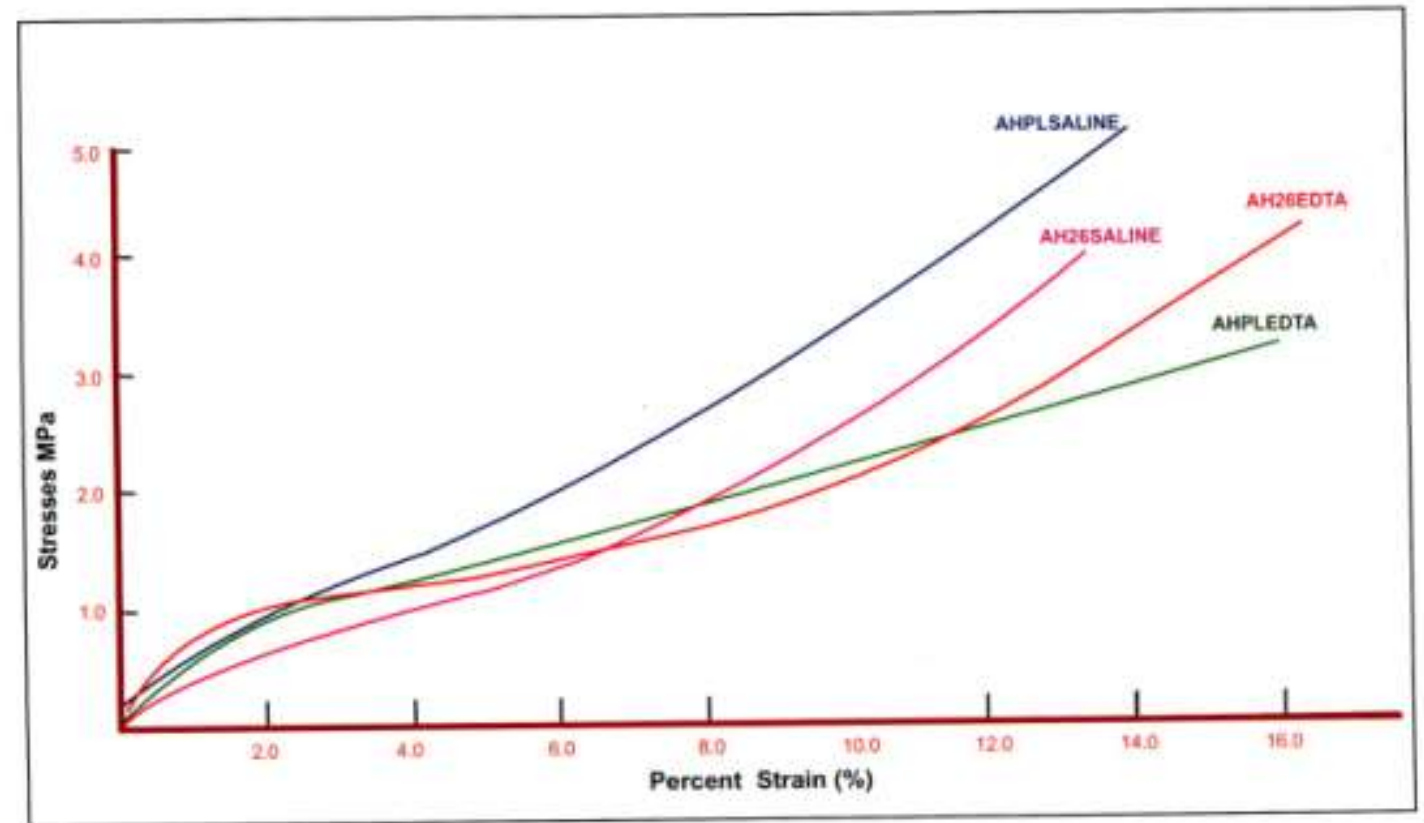

Fig-5 - stess- strain graph

$0.9 \%$ SAL.INE

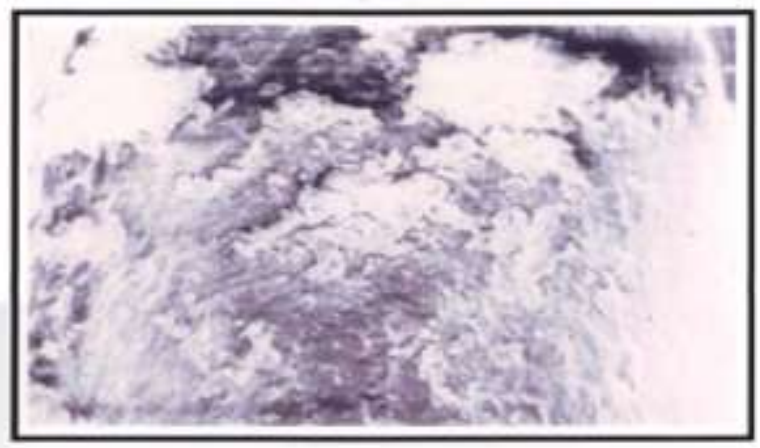

Fig 6-Smear layer.

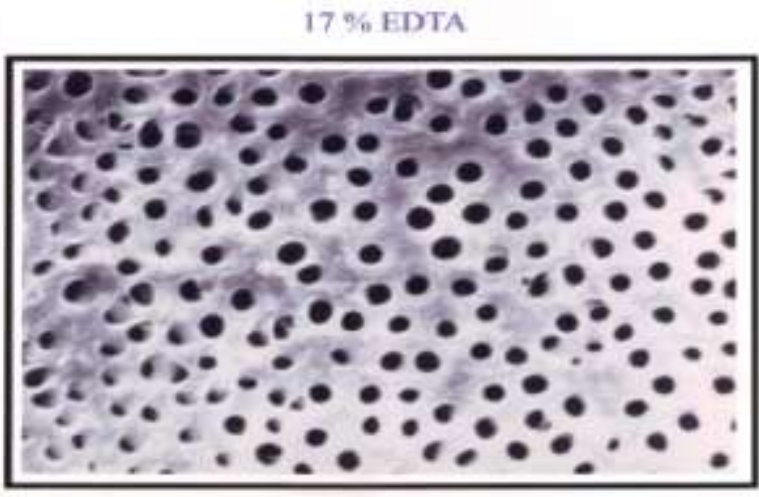

Fig 7-17\% EDTA treated dentin showing smear layer removal \& open dentinal tubules. 


\section{SEM Evaluation}

The specimen treated with $0.9 \%$ physiological saline showed the presence of smear layer covering all dentinal tubules on SEM observation. The specimen which had been treated with 17\% EDTA showed clean open tubules with no smear layer.

\section{Discussion}

A wide variety of endodontic sealer cement is available to the profession and at present epoxy resins based sealers possess very good physical properties, excellent apical sealing and ensure adequate biological performance. Epoxy resin based sealers have been introduced in endodontic practice because of the favourable characteristics, such as adhesion to the tooth structure, long working time, ease of mixing and good sealing ability.AH-26, demonstrated excellent bonding strength to dentin.AH-26 mainly contains Bismuth oxide and hexamethylene tetramine as powder and Bis Phenol diglycidyl ether as resin. AH Plus, due to its excellent properties, such as low solubility, small expansion, adhesion to dentin and very good sealing ability is widely used in root canals. The material consists of two pastes, easy to manipulate, adapts well to the root canal walls and is claimed to prevent long term dimensional stability. AH Plus is also popular for its tissue compatibility.

Most previous studies have investigated the ability of endodontic sealers to prevent apical leakage $[8,9]$. However, it has been shown that different leakage evaluation methods may exhibit different results on the same sealer. In addition, leakage studies do not allow determination of which of the two interfaces, dentinsealer or gutta-percha sealer, is leaking. They also do not give any insight into the mechanism that may lead to apical sealing . [10]. Root filled immature roots or roots that are otherwise weakened internally run a greater risk of fracture. With the introduction of adhesive filling techniques, attempts have been made to strengthen such teeth through reinforcement of the coronal part of the root by composite cements and fillings. Pashley et al [11] concluded that tensile testing produced more uniform stressing than shear testing. According to this study, a reproducible method was used in the present investigation to measure the tensile bond strength of endodontic sealers to gutta-percha. Considering the disadvantages of leakage studies and the fact that greater adhesion of sealers to gutta-percha can prevent apical leakage, the present study was designed to investigate the adhesive ability of AH Plus and AH-26 endodontic sealers to dentin by measuring their tensile bond strengths, and to evaluate the effect of smear layer on the adhesion of the endodontic sealers.

The tensile bond strength of groups I and II have been calculated and it was found that there was no statistical difference between them. However numerically group II, where AH -26 sealer was used in conjunction with EDTA, with smear layer removal showed increase in tensile bond strength than group II (AH Plus saline group).The positive effect of EDTA on the tensile bond strength of AH-26 sealer may be explained by the probability that smear layer removal by EDTA exposed dentinal tubules creating a much more irregular surface compared with those samples, when the smear layer was left intact. This irregular surface produced greater adherence of AH-26 to the dentin which is due to the physical interaction of the sealer to dentin through a micromechanical interlocking. The epoxy resin based AH-26 sealer is thought to be able to react with any exposed amino groups in collagen to form chemical bonds between the resin and collagen when the epoxide ring opens. The potential of this chemical bonding due to ring opening explains the higher bond strength of AH-26 which is consistent in many studies. Studies have shown a significant increase in adhesive strength and resistance to micro leakage of AH26 sealer when the smear layer was removed. Other investigators assessed the penetration depth of different sealers into the dentinal tubules. They found the penetration to be 10 to $80 \mu \mathrm{m}$ after removal of the smear layer, whereas no penetration was observed with the smear layer intact. [12]The study by Andreas B Kokkaset al also throws light on the significance of smear layer removal on the depth of penetration of the sealer. [13].

On the other hand the AH Plus group behaved differently to the presence of smear layer. In fact higher bond strength was recorded when dentin had been treated with saline compared to the smear layer removal group. This was interpreted as an enhancement of adhesion of sealers to dentin in the presence of smear layer. The opening of dentinal tubules and loss of smear layer was apparently not favourable process for improving adhesion of sealer. The possible explanation for reduction of adhesion may be that the opened dentinal tubules acted as stress risers, which promoted failure in the adhesive joint. These failures result from locally high stresses in specific areas and contribute to the propagation of adhesive failure. This mode of adhesive failures have been reported by the Iman M Saleh. [14] He studied the adhesion of endodontic sealers and found that penetration of endodontic sealers into dentinal tubules when the smear layer was removed was not associated with higher bond strength.

Saleh I M et al[15] studied the adhesion of root canal sealers to dentin together with effect of various dentin pretreatments. It was shown that removal of smear layer impaired sealer adhesion to dentin. Different sealer types require different pre-treatment's for optimal adhesion.

AH Plus is a two paste system on which the manufacturer had set the viscosity of the material. It exhibited greater flow rate and faster setting time than AH-26.This caused shrinkage stresses and earlier debonding from the 
dentinal walls. This was reported by Zmener O Speilberg in his study of the sealing properties of epoxy resin based root canal sealers. [16].

For a good adhesion, the adherent surface should be clean and smooth to enable intimate contact between it and adhesive. AH Plus sealer showed superior adhesion to the dentin in the presence of smear layer supporting this fact. The smear layer at low magnification has a typical amorphous structure and at higher magnification a globular pattern. It has been suggested that a bond develops between the material and the smear layer. The strength of bond may be determined and limited by the strength of forces holding the globules to each other and to the underlying dentin.

It should be noted that at present there is no data concerning the minimal required shearing or tensile bond strength of sealers. There is an obvious need for an International standard for bonding values of endodontic sealers, keeping in mind the poor adhesion of many currently marketed products.

Adhesive strength is only one aspect of the root canal sealers. Further investigations of the various aspects of the root canal sealer is necessary. Which sealers seal better in the presence of smear layer or its absence is one specific area which needs further evaluation. The present evaluation have examined one aspect of the question of which sealer is best in terms of adhesion to dentin with and without the presence of smear layer.

\section{CONCLUSION}

In this study it was found that the tensile bond strength of $\mathrm{AH} 26$ root canal sealers increased after smear layer removal while that of AH Plus showed converse relation. Comparison of the strength properties of AH26 and AH Plus showed bond strength values which were not statistically significant. However this, being an In Vitro study the results cannot be directly transposed to In vivo conditions. The present study confirms the suggestion that micromechanical retention by penetration of sealer tags is not the only and may not be an important factor affecting adhesion of root canal sealers and rather the physical integrity of the sealer may be more important. Clearly further research is necessary to study the properties of different sealer cements, in order to establish the factors that affect and determine their clinical usefulness.

\section{References}

[1]. Grossman L.I-Endodontic practice $7^{\text {th }}$ edition( Philadelphia:Lea \&febiger/1970; 329-77.)

[2]. Orstavik D,Erikson HM,Beyer Olsen EM, Adhesive properties and leakage of root canal sealers in vitro, Int Endod J 1983;16:5963

[3]. De Gee AJ,Wu M-K,Wesslin K PR, Sealing properties of Ketac Endo glass Ionomer cement and AH 26 root canal sealers, Int Endod J 27,1994,239-44

[4]. Timpawat S, Hamirattisai C, Senawongs P, Adhesion of a glass-ionomer root-canal sealer to the root-canal wall. Journal of Endodontics 27,168-71.

[5]. Sen BH, Wesselink PR, The smear layer: aphenomenon in root-canal therapy. International Endodontic Journal(1995),1 28,141-146

[6]. Gettleman BH, Messer HH, ElDeebME Adhesion of sealer cements to dentin with and without the smear layer. Journal of Endodontics , (1991) $17,15-20$

[7]. Iman M SalehI.EyesteinRuyter,Adhesion of endodontic sealers-scanning electron microscopy and energy dispersive microscopy. Journal of Endodontics2003;29:595-601

[8]. Orstavik D, Eriksen HM, Beyer-Olsen EM. Adhesive properties and leakage of root canal sealers in vitro. IntEndod J 1983;16:59-63

[9]. Pashley D, Camps J. Apical leakage of four Endodontic sealers. J Endod 2003;29:208-10.

[10]. Lee KW, Williams MC, Camps JJ, Pashley DH. Adhesion of endodontic sealers to dentin and gutta-percha. J Endod 2002;28:684-7.

[11]. Pashley D, Camps J. Apical leakage of four Endodontic sealers. J Endod 2003;29:208-10.

[12]. Kouvas V,Liolios E,Vassiliadisl,Parissis-Messimeris-Influence of smear layer penetration of three endodontic sealers-An SEM Study-Endodo Dent Traumatol 1998;14:191-5

[13]. Andreas B Kokkas The influence of smear layer on dentinal tubule penetration depths by three different root canal sealers- An In Vitro study Journal of Endodontics2004;30:100-2

[14]. Iman M SalehI.EyesteinRuyter-Adhesion of endodontic sealers-scanning electron microscopy and energy dispersive microscopy. Journal of Endodontics2003;29:595-601

[15]. Saleh IM, -866Ruyter IE, Haapasalo M, Orstavik D. The effects of dentine pretreatment on the adhesion of root canal sealers. IntEndod J.2002;35-859

[16]. Sealing properties of a new epoxy resin-based root-canal sealer.Zmener 0,Spielberg CLamberghini F- IntEndod J 1997;sept 30(5):332-4 